\title{
AUTORITARISMO E EDUCAÇÃO NO BRASIL: AS REFORMAS EDUCACIONAIS NA DITADURA CIVIL-MILITAR (1964-74)
}

\begin{abstract}
Cláudia Regina VARGAS claudiarvargas@ hotmail.com Doutorando em Educação pela Universidade Federal de São Carlos
\end{abstract} Marcelo Gonzaga dos SANTOS marcelomalcon.ufscar@gmail.com Mestrando em Educação pela Universidade Federal de São Carlos

RESUMO: O presente artigo vem demonstrar que tanto a legislação educacional, como os planos governamentais para a área, refletem as continuidades e mudanças no regime político brasileiro e, por isso, tomando-se por base a sua análise, é possível avaliar o papel específico dos militares no cenário da produção e transmissão das políticas educacionais no período de 1964 a 1974.

Palavras-chave: História da Educação no Brasil, regime militar, política educacional, reformas educacionais.

ABSTRACT: The present paper demonstrates that the educational legislation, as well as the governmental plans for the area, reflects the continuities and changes in the Brazilian political regimen and, therefore, taking into account its analysis, it is possible to evaluate the specific role of the military in the scenario of the production and transmission of the educational politics in the period of 1964 through 1974.

KEYWORDS: History of Education in Brazil, military regimen, educational politics, educational reforms.

Conforme procuraremos expor nos próximos parágrafos, a educação formal foi atingida por um número bastante grande de mudanças durante a vigência do regime autoritário (1964-84). Talvez a principal delas, porque influenciou de forma permanente todas as demais, tenha sido o ingresso, ou melhor, a substituição dos professores pelos "planejadores” nas instâncias de decisões de políticas governamentais. 
O aumento da participação dos planejadores em detrimento dos educadores indica, também, a visão compartilhada pelos militares - pelo menos aqueles que estavam no poder sobre a sociedade e sobre a organização estatal que melhor responderia à relação entre público-privado. Sobre isso, Saviani (2008, p. 383) destaca:

\begin{abstract}
A essa teoria pedagógica correspondeu uma reorganização das escolas que passaram por um crescente processo de burocratização. Acredita-se que o processo se racionaliza à medida que se agisse planificadamente. Para tanto, era mister baixar instruções minuciosas sobre como proceder com vistas a que os diferentes agentes cumprissem cada qual as tarefas específicas acometidas a cada um no amplo espectro em que se fragmentou o ato pedagógico.
\end{abstract}

Essa transformação levou à perda de capacidade dos educadores, membros do Ministério da Educação, em influir de maneira significativa nos ramos da educação e no planejamento educacional no Brasil. O MEC, órgão importante da formulação de políticas educacionais, teve sua credibilidade abalada. Cada professor e cada especialista de educação passou a ser visto, pelos militares, como inimigo em potencial, que deveria ser mantido sob estreito controle e rigorosa vigilância. Ainda, segundo Saviani (2008, p.383):

O controle seria feito basicamente pelo preenchimento de formulários. O magistério passou, então, a ser submetido a um pesado e sufocante ritual, com resultados visivelmente negativos. Na verdade, a pedagogia tecnicista, ao ensaiar transpor para a escola a forma de funcionamento do sistema fabril, perdeu de vista a especificidade da educação, ignorando que a articulação entre escola e processo produtivo se dá de modo indireto e por meio de complexas mediações. Além do mais, na prática educativa a orientação tecnicista cruzou com as condições tradicionais predominantes nas escolas bem como com a influência da pedagogia nova, que exerceu poderoso atrativo sobre os educadores.

Entretanto, como não podia deixar de ser, a simples transferência dos objetivos econômicos para o seio da educação, representada pela elevação dos "planejadores" aos postos de decisão, redundou em perdas para o desenvolvimento do ensino no Brasil, mas também funcionou como um dos primeiros mecanismos de demonstração da contradição do sistema vigente. Neste particular, Kuenzer (1989, p.41) registrou que:

A legislação educativa é toda reformulada, economistas de plantão passam a fazer sucesso como educadores e em nome da eficiência de todo sistema são elaborados planos de toda a sorte. Do primário à pós-graduação, nada fica 
sem o dedo dos planejadores. A grandiosidade das propostas, em contraposição aos modestos resultados obtidos, acelera a crise de credibilidade do Planejamento Educacional e dos planejadores, de tal sorte que a consciência dessa inadequação se dá muito antes da percepção da crise global do modelo de desenvolvimento.

Já no governo de Castelo Branco, a preocupação com o ensino é elevada a categoria de prioridade. Começa, neste governo, um longo processo de transformação do campo educacional representado pelos acordos MEC-Usaid, cobrindo todo o espectro da educação nacional (ensino primário, médio e superior), com treinamento de professores e com a produção e veiculação de livros didáticos. Estas mudanças, como mais adiante veremos, iriam redundar em uma verdadeira desnacionalização da educação brasileira.

É no bojo deste processo que o governo promove a Primeira Conferência Brasileira de Educação, em março de 1965. No discurso de abertura, o presidente Castelo Branco salientou que o governo tem recebido "aplausos por estar repondo a ordem no sistema educacional" (Branco, 1965, p.112). Isto mostrava que o projeto posto em prática atingia seus objetivos de legitimação de um regime político reformulado.

A busca de legitimação implicava em convencer a sociedade de que os acordos que estavam sendo feitos objetivavam a integração nacional mediante da capacitação para o trabalho e a defesa da sociedade capitalista. Este era tanto o sentido da promoção da Conferência quanto dos discursos governamentais apresentados em seu interior. Ao afirmar que a sociedade manifestava-se favoravelmente às reformas, o Presidente pretendia apontar que a "revolução" estava cumprindo seus objetivos e sendo, portanto, apoiada pela Nação.

Entretanto, esta não era a visão dos analistas. Estas apontavam que por detrás da retórica estava ocorrendo um processo que, em longo prazo, levaria à transformação de um direito básico do cidadão (o acesso à escola) em privilégio das camadas favorecidas pelo sistema econômico, com o Estado se eximindo de suas responsabilidades para com a sociedade. Segundo, Germano (1993, p. 123-4):

(...) na esteira dos acordos MEC-Usaid foi constituído um grupo de trabalho denominado Equipe de Assessoria e Planejamento do Ensino Superior (EAPES). Tal equipe produziu um documento, concluído em 1968, que continha análises sobre a educação brasileira e proposições acerca da reforma universitária. O relatório partia do pressuposto de que a educação era essencial ao desenvolvimento econômico da sociedade e sugeria a adoção de medidas, tais como: sistema de créditos, organização departamental, ciclo básico e ciclo profissional etc. Ao lado disso, concedia 
também grande ênfase à privatização do ensino. Esta seria uma forma de expandir as oportunidades educacionais, funcionando as escolas privadas como complementares à ação do Estado. Dessa maneira, constava do relatório da EAPES a defesa da gratuidade do ensino público apenas no tocante ao primário, conforme explicitava a Constituição de 1967. Nos níveis secundário e superior, o ensino público deveria ser gratuito apenas para aqueles que provassem falta de recursos.

Dois grandes acontecimentos marcaram o final dos anos 60: as manifestações estudantis e as ações do governo para contê-las. Em 1968, o movimento estudantil chegava ao seu ápice com grandes manifestações e reivindicações por parte dos estudantes. Mas estes não estavam sozinhos, artistas, políticos da oposição, operários, profissionais liberais, enfim, a uma parte da sociedade civil que não concordava com o governo dos "homens de farda", se uniram nessas manifestações. Os estudantes reivindicavam o aumento nos números de vagas nas universidades, já que muitos, mesmo estando aptos para cursarem uma graduação, não a conseguiam por não haver vagas suficientes. Influenciados pela efervescência das manifestações estudantis em todo o mundo, parte da juventude brasileira passa a ser uma "pedra no sapato" do governo militar. Desta forma, o governo civil-militar introduz uma série de medidas no campo educacional que intencionavam o controle desses movimentos. Desde o início do governo autoritário, os militares sempre se preocuparam com a reordenação das formas de controle social e político. Nesse sentido, Barbara Freitag(2005, p.134-135) afirma que:

As primeiras diretrizes formuladas por este governo, norteadoras da futura política educacional, já foram fixadas no início do governo Castello Branco. Estão contidas nas declarações feitas pelo Presidente aos Secretários de Educação de todos os Estados, em meados de 1964: o objetivo do seu governo seria restabelecer a ordem e a tranqüilidade entre estudantes, operários e militares. Excluindo o grupo dos militares podemos dizer que com a nova legislação, promulgada pelo governo militar, visa-se de fato criar um instrumento de controle e de disciplina sobre estudantes e operários.

Além disso, a aceleração do crescimento econômico do modelo capitalista brasileiro também levou à imposição de políticas educacionais, consubstanciadas nas reformas de 1968 e de 1971. Assim como, as eleições parlamentares de 1970 atestaram o ápice da popularidade do Regime Militar, a economia cresceu impulsionando a ideia de "Brasil-potência". "O clima reinante no país" se caracterizava, "ao mesmo tempo, por uma combinação de medo da 
repressão do Estado e de euforia em decorrência do crescimento econômico" (GERMANO, 1993, p.160).

Ao mesmo tempo em que ocorriam essas discussões, o governo baixava, em dezembro de 1968, o Ato Institucional n.5 e no ano seguinte o seu descendente direto, o Decreto-Lei $477^{1}$. Ambos representaram a expressão mais acabada das ameaças da repressão política e ideológica por parte do governo em relação, especialmente à universidade brasileira, mas que atingiu todo o ensino formal.

Não é só porque o filho direto do AI-5, que o Decreto-Lei 477/69 é importante para a nossa discussão. Para além da conjuntura, esta nova legislação talvez seja a que indique melhor o processo de militarização do ensino no Brasil, pois o seu principal antecedente foi o Relatório Meira Matos, que recomendava uma série de medidas para conter a "subversão nas escolas", escondida quase sempre na insistência por "liberdade de cátedra". Entretanto, não é pelo que é dito no Relatório que ele representa um avanço castrense sobre setores especificamente civis do Estado, mas sim porque ele é elaborado sob a direção de um membro do Exército, considerado por este como um revolucionário de primeira ordem.

Nessa conjuntura, diferentes analistas mostram que o Estado autoritário investiu na desqualificação dos profissionais da educação e aperfeiçoou o controle técnico e burocrático sobre o ensino em seus diferentes graus. Como exemplo deste último, pode-se citar medidas como: subordinação dos professores aos supervisores e orientadores pedagógicos; massificação e imposição do material didático em nível nacional. Porém, o exemplo emblemático da visão militar sobre o papel da educação na formação de novos sujeitos sociais, foi dado pela criação das disciplinas de Educação Moral e Cívica $-E M C-\left(1^{\mathrm{a}}\right.$ a $6^{\mathrm{a}}$ série do $1^{\circ}$ grau) e Organização Social e Política do Brasil -OSPB- $\left(7^{\mathrm{a}}\right.$ e $8^{\mathrm{a}}$ série do $1^{\mathrm{o}}$ grau, ensino médio e superior), através da Lei 770 de outubro de 1968. Os objetivos expressos do ensino de EMC e OSPB eram a introdução dos ideais de civismo e patriotismo nos educandos.

Os objetivos do Governo eram nitidamente evidenciados nos documentos do Conselho Federal de Educação (CFE), editados em Documenta, publicação oficial desse órgão. Ao longo da coleção de 1964 a 1974, pudemos perceber um ligeiro aumento da preocupação do

\footnotetext{
${ }^{1}$ No Decreto-Lei isto é dito textualmente, pois é com base nas atribuições dadas pelo AI-5 que o Presidente baixa a nova lei.
} 
Governo. Esta preocupação centrou-se basicamente sobre o conteúdo das disciplinas que objetivavam a construção do "homem integrado", função primordial da disciplina EMC ${ }^{2}$.

Os "homens de verde" objetivavam para o ensino dessas matérias de ensino a introdução dos ideais de civismo e patriotismo nos educandos. Esta preocupação centrou-se basicamente sobre o conteúdo das disciplinas que objetivavam a construção do "homem integrado", , função primordial da área de moral e civismo. Nesse sentido, pode-se ressaltar algumas finalidades da EMC contidas no Art. $2^{\circ}$ do Decreto-Lei n. ${ }^{\circ}$ 869/69:

d) o culto à pátria, aos seus símbolos, tradições, instituições e aos grandes vultos de sua história;

e) o aprimoramento do caráter, com apoio na moral, na defesa à família e à comunidade.

g) o preparo do cidadão para o exercício das atividades cívicas, com fundamento na moral, no patriotismo e na ação construtiva, visando o bem comum;

h) o culto da obediência à lei, da fidelidade ao trabalho e da integração na comunidade.

Destas acepções, pode-se ressaltar que o cidadão que os militares pretendiam formar remete a uma concepção positivista, onde o homem deve se adequar à sociedade em que vive. Portanto, o indivíduo deve se integrar, ou seja, incorporar-se à sociedade ${ }^{4}$. Deste modo, o regime autoritário e as elites burguesas dominantes garantiriam a manutenção da ordem e do status quo. A educação escolar passou a ser uma importante ferramenta de intervenção do projeto ideológico do Estado Autoritário. Tal projeto não ficará restrito só na implantação das disciplinas de EMC, OSBP e EPB. À criação dos Centros Cívicos Estudantis, o culto aos símbolos cívicos (Lei 5.700/71), a Educação Física e o Ensino Religioso também foram utilizadas para alcançar os objetivos propostos pelos técnicos do governo ditatorial.

\footnotetext{
${ }^{2}$ Desde 1961 e, portanto, antes do golpe militar, a educação moral dos cidadãos é objeto de análise por parte do CFE, conforme expresso em diversas reuniões deste Conselho reproduzidos em Documenta. Todavia, o que se percebe nestas discussões é a preocupação de introduzir o ensino moral e cívico a partir de outras disciplinas e tendo como plano de fundo a criação de bons cidadãos (nem sempre se define o que seja "bom cidadão"). A diferença, agora, está na insistência com que o tema é tratado e na exigência de ampliar o espaço reservado por uma disciplina cujo objetivo expresso fosse à educação cívica e esta fosse obrigatória para todos os educandos, cujo conteúdo seria determinado diretamente pelo governo federal. A título de ilustração, lembramos que a tarefa de construir currículos comuns e até escrever os primeiros textos coube a um oficial do exército (Enjolrás Camargo)

${ }^{3}$ Termo utilizado em discurso por Jarbas Passarinho, ex-ministro da educação do governo do general-presidente Emílio Garrastazu Médici (1969-1974), em cuja gestão foi elaborada uma das principais reformas educacionais da ditadura militar: a 5692/71 (PASSARINHO, 1973).

${ }^{4} \mathrm{Na}$ busca pela legitimidade do regime, a educação também assume a função de formar futuros eleitores.
} 
Com a obrigatoriedade das disciplinas EMC e OSPB, os estabelecimentos de ensino são levados a diminuir a carga horária das disciplinas História e Geografia e a apressar a retirada dos currículos de segundo grau das disciplinas Sociologia e Filosofia, a fim de cumprir o programa fixado pelo Conselho Federal de Educação.

O projeto de educação formulado durante o regime autoritário, além de impor o ensino de EMC e OSPB como prática educativa no $1^{\circ}$ e $2^{\circ}$ graus, institui também as licenciaturas curtas em Estudos Sociais, substituindo as disciplinas de História e Geografia no $1^{\circ}$ grau. Isso implicou na desqualificação dos professores dessas disciplinas e na degradação do conteúdo programático das mesmas.

Outro exemplo da ação do Estado tecnocrático sobre a educação é o Movimento Brasileiro de Alfabetização (Mobral), criado em 1967, mas que só começa a funcionar em 1970, perseguindo, uma vez mais, a erradicação do analfabetismo de jovens e adultos. Foi lançado com grande alarde, pois visava atingir um grande contingente popular. O objetivo não declarado- era a criação de novos contingentes eleitorais através da integração dos recémalfabetizados ao universo político-partidário. Assim, este programa constituía-se em mais uma maneira de consolidar o poder político vigente, em uma forma de buscar a legitimação.

O Mobral nasceu em uma conjuntura diferente daquela que predominou na segunda metade da década de 60. As eleições parlamentares de 1970 atestaram a popularidade do Regime Militar. A economia cresceu impulsionando a ideia de "Brasil-potência". Para Germano, "o clima reinante no país" se caracterizava, "ao mesmo tempo, por uma combinação de medo da repressão do Estado e de euforia em decorrência do crescimento econômico" (GERMANO, 1993, p.160). Parte das lideranças estudantis, dos intelectuais de esquerda e, em escala bem menor, das lideranças operárias havia se engajado no combate armado contra a ditadura, expressando a redução vertiginosa da confiança nos mecanismos de luta dentro da legalidade. Com isto o caminho das "reformas de bases", entre as quais a reforma educacional foi deixada de lado. A questão da educação passava a ser algo secundário ou mesmo "inexistente".

É dentro deste panorama que a reforma do ensino de $1^{\circ}$ e $2^{\circ}$ graus, consubstanciada na Lei 5692/71, foi recebida com entusiasmo pelos educadores e pelos parlamentares, não somente da Arena como do próprio MDB. Pellanda (1986, p.55) afirma que:

A Lei 5692 (...) estava em perfeita harmonia com a situação econômica e política vigente na época. A nova orientação garante o controle do ensino 
através de estratégias do tipo ensino mecânico, formal e estranho à vida. Essas estratégias além de impedirem o desenvolvimento do pensamento crítico e da realidade social têm também como consequiência o afastamento dos alunos pobres da escola já nos primeiros anos por não agüentarem a distância do ensino de sua realidade imediata. Num outro nível, os alunos que têm um pouco mais de recursos, afastam-se da escola um pouco mais tarde não podendo, em sua grande maioria, chegar à universidade, o que estaria também garantindo a elitização do ensino superior.

Apesar da adesão que a Lei encontra, o objetivo do governo era muito mais o de criar "postos de trabalho" - visando, por conseguinte, a manutenção do apoio dos empresários - do que responder às falhas da Lei anterior. Isto é mostrado quando se atenta para o fato de que é com base nesta reforma que são introduzidos os cursos profissionalizantes que, se de um lado ampliam a capacidade de absorver mão-de-obra, por outro, reduzem as chances do jovem, principalmente os de baixa renda, de ingresso na universidade.

Neste mesmo sentido, é possível, segundo Germano, notar o caráter privatizante contido na Lei 5692/71, já que a transformação dos cursos de $2^{\circ}$ grau em ensino profissional implicava em investimentos crescentes e imediatos no setor ${ }^{5}$. Como tais investimentos não eram prioritários para o Estado, coube à iniciativa privada criar e manter os melhores cursos. Como conseqüência, isto concorreu decisivamente para a desqualificação das escolas públicas de $1^{\circ}$ e $2^{\circ}$ graus, contribuindo para ampliar a distância entre as classes sociais. Sobre essa questão, Ferreira \& Bittar (2006, 1165-66) destacam que:

(...) o crescimento econômico acelerado do capitalismo brasileiro durante a ditadura militar impôs uma política educacional que se materializou, em linhas gerais, nas reformas de 1968 e de 1971, cujos efeitos engendraram uma nova categoria docente e, por conseguinte, no exercício da profissão em parâmetros distintos dos anteriores. Os professores formados nos cursos de licenciaturas curtas das faculdades privadas noturnas substituíram a pequena elite intelectualizada das poucas escolas públicas antes existentes. A extensão da escolaridade obrigatória de quatro para oito anos ocasionou a rápida expansão quantitativa da escola fundamental, exigindo, para o seu atendimento, a célere formação dos educadores, o que se deu de forma aligeirada. A combinação entre crescimento quantitativo, formação acelerada

\footnotetext{
${ }^{5}$ Nesta direção, alguns analistas destacaram anos depois: "Uma profissionalização eficiente não pode ser improvisada. O seu sucesso depende, basicamente, de uma sólida reciclagem dos recursos humanos disponíveis e de uma efetiva inversão de capital em instalações e equipamentos, necessários à montagem de um sistema de ensino profissionalizante (...). Isto significa que a transformação de toda a rede de ensino de $2^{\circ}$ grau em profissionalizante implicaria um aumento substancial dos recursos financeiros que o Estado não estava em condições de suportar." (Leite \&Savi, 1981, p.5).
} 
e arrocho salarial deteriorou ainda mais as condições de vida e de trabalho do professorado nacional do ensino básico, tanto é que o fenômeno social das greves, entre as décadas de 1970 e 1980, teve como base objetiva de manifestação a própria existência material dos professores públicos estaduais de $1^{\circ}$ e $2^{\circ}$ graus.

Em 1971, dada a brutal repressão do Estado, a oposição armada estava praticamente exterminada, e a oposição legal, calada. O clima era de euforia nacional. No ano anterior, o Brasil havia conquistado o tri-campeonato mundial de futebol, com sua famosa marchinha Prá Frente Brasil. O Governo Médici desenvolvia projetos arrojados, como a construção da rodovia Transamazônica, justificando o slogan "este é um país que vai prá frente". Nesse sentido, Saviani (2008, p. 374) afirma:

O crescimento econômico acelerou-se, configurando o que foi chamado de "milagre brasileiro". Os militares forjaram as palavras de ordem "Brasil grande" e "Brasil potência", criando um clima de euforia favorecido pela vitória da seleção brasileira na Copa do Mundo realizada no México, conquistando definitivamente a Taça Jules Rimet. Foi, portanto, sob a égide da estratégia "autoritarismo triunfante" que se deu a elaboração e a aprovação do projeto da Lei n. 5692, de 11 de agosto de 1971, que instituiu as diretrizes e bases do ensino de primeiro e segundo graus, reformando o antigo ensino primário e médio.

Tudo isso faz parte do quadro histórico em que a reforma do ensino de $1^{\circ}$ e $2^{\circ}$ graus vai ser definida. Por meio da avaliação das reuniões do C.F.E., vemos que há a preocupação clara em responder aos desafios colocados pela inserção do Brasil numa nova forma de organização do mercado de trabalho. É a isto que responde a promulgação da Lei 5692/71, que, como já indicamos, apresenta dois pontos fundamentais: a extensão da escolaridade obrigatória ( $1^{\circ}$ grau) e a generalização do ensino profissionalizante no $2^{\circ}$ grau.

Assim, o governo militar procura mostrar que ele compartilha de um real interesse em melhorar o ensino primário e médio, e, através destes, melhorar as condições de vida das grandes massas. Jarbas Passarinho (1973, p.11), quando ocupava a pasta da Educação, enfatizava este aspecto:

O desafio é duplo. De um lado, modernizar a Educação em todos os aspectos - em seus fins, em seu conteúdo, em seus métodos, em sua inspiração geral , dela fazendo para os cidadãos um instrumento eficaz na busca da felicidade e, para a Nação, um real fator de trabalho, de paz, de progresso. De outra parte, proporcioná-la assim melhor a um número cada vez maior de brasileiros - e a todos num estágio básico de estudos comuns, que se amplia 
- como requisito para sua verdadeira inserção na comunidade nacional (...) constata-se com nitidez a preocupação de que o ensino propicie a formação básica da personalidade, dando ao aluno condições de auto-realização e, ao mesmo tempo, possibilitando-lhe uma participação social efetiva e harmoniosa pelo exercício consciente da cidadania e pela capacitação real para uma atividade profissional.

A Lei 5692 assume uma configuração mais radical no que diz respeito à preparação para o trabalho. Neste caso, a tensão percebida entre técnicos e educadores se refere à ênfase emprestada ao ensino profissionalizante. Enquanto para aqueles, como esclarece a citação de Jarbas Passarinho, ela é fundamental para a construção do "homem integrado", para esses ela funciona como mecanismo de aprofundamento das desigualdades sociais.

A alfabetização de adultos, além do ensino voltado ao trabalho, tem como principal objetivo formar eleitores. São vários os programas elaborados entre 1967 e 1973, tendo como principais o Mobral, o Projeto Minerva e a Televisão Educativa.

Durante o governo militar, a "parada" é ganha pelos técnicos que, através de suas ações conseguem convencer a população que a educação está melhor sob a "batuta das espadas" do que estava antes. Todavia, já em 1982, os educadores voltam a exercer papel privilegiado no C.F.E., promovendo ações que levaram à reformulação do ensino profissionalizante e ao aumento de importância do ensino das disciplinas ligadas à crítica social, como História, Filosofia, Sociologia, etc.

De qualquer forma, conforme pensamos ter indicado, as mudanças no processo de ensino no Brasil no período autoritário tinham um endereço bastante claro: legitimar um regime de base militar através da integração social promovida pela educação para o trabalho.

\section{REFERÊNCIAS}

BRANCO, H.C. Discurso de Abertura da Primeira Conferência Brasileira de Educação. Documenta, Rio de Janeiro, v.36, p.112-3, abr. 1965.

. Poder Legislativo. Decreto-Lei no 869, de 12 de setembro de 1969. Dispõe sobre a inclusão da Educação Moral e Cívica como disciplina obrigatória, nas escolas de todos os graus e modalidades, dos sistemas de ensino no País, e dá outras providências.Diário Oficial. Brasília, 15 de set. de 1969. Disponível em: <http://www6.senado.gov.br/legislacao/ListaPublicacoes.action?id=195811 >. Acesso em: 13 de out. 2010. 
CUNHA, L.A. Educação e desenvolvimento social no Brasil. 7.ed. Rio de Janeiro: Francisco Alves, 1993.

CUNHA, L.A., GÓES, M. O golpe na educação. Rio de Janeiro: Zahar, 1985.

DOCUMENTA. Brasília, Conselho Federal de Educação, 1964-74, n.22-169.

FERREIRA JR., Amarilio\& BITTAR, Marisa. A ditadura militar e a proletarização dos professores. Educ. Soc. [online]. 2006, vol.27, n.97, pp. 1159-1179. ISSN 0101-7330.

FREITAG, Barbara. Escola, Estado e sociedade. 7 ed. São Paulo: Centauro Editora, 2005.

GARCIA, W.E. Educação brasileira contemporânea: organização e funcionamento. 3.ed. São Paulo: Mc GRAW-HILL, 1978.

GERMANO, J.W. Estado militar e educação no Brasil (1964-1985). São Paulo: Cortez; Campinas: Unicamp, 1993.

KUENZER, A. ET AL. Planejamento e educação no Brasil. 2. ed. São Paulo: Cortez, 1989.

LEI de Diretrizes e Bases da Educação Nacional e o Magistério. 4.ed. Porto Alegre:

Sulina, 1972.

LEITE, M.R., SAVI, R.C.B. Ensino de $2^{\circ}$ grau profissionalizante. Cadernos de Pesquisa, São Paulo, v.36, p.3-26, 1981.

PASSARINHO, J. Aspectos do ensino de $\mathbf{1}^{\circ}$ grau. Brasília: MEC, 1973.

PELLANDA, N.M.C. Ideologia, educação e repressão no Brasil pós-64. Porto Alegre: Mercado Aberto, 1986.

PRADO JÚNIOR, B. et AL. Descaminhos da educação pós-68. São Paulo: Brasiliense, 1980.

SAVIANI, Dermeval. História das idéias pedagógicas no Brasil. 2. ed. Campinas, SP: Autores Associados, 2008. 